\title{
12 | Environmental perception and political mobilization in Rio de Janeiro and São Paulo: a comparative analysis
}

\author{
ANGELA ALONSO AND VALERIANO COSTA
}

This chapter discusses the processes that shape citizen engagement in scientific and technical issues in Brazil, focusing on an environmental case. Such engagements can take the form of movements or 'mobilizations' to resist planned interventions because of their environmental or related social implications. Brazilian sociologists have explained such environmental mobilizations by focusing either on the intentions of environmental actors (Viola and Leis 1995) and the diffusion of particular values, or the construction of perceptions of environmental risk (Fuks 1998; Guivant 1998). Both these approaches offer only partial explanations, however, because they ignore the socio-political dimensions of mobilization, and how particular forms of knowledge become linked with mobilization practices. Thus both fail to address the central problem: what explains mobilization itself? Given a particular technical issue, why does mobilization occur in some instances, yet not in others?

In this chapter, we argue that three sets of issues are important in shaping the conditions for environmental mobilization, and its effectiveness or otherwise: the 'mobilizing structure' available to activists and citizens; the political arrangements with which mobilization interacts; and the social construction of environmental risks, especially the relationship between the knowledge and values of affected actors and the claims made by scientific and technical discourses.

Our arguments are based on the evidence from case studies of efforts to build circular highways, or beltways, in Rio de Janeiro (the Niemeyer project) and São Paulo (the Rodoanel project). Environmental mobilization emerged to block the former successfully, but not the latter. The chapter explores the reasons for these differences.

\section{Our approach}

The extent of political activity in any society is extremely varied, both in terms of who engages in it, and over time. As theorists of 'contentious politics' note, social life is riddled with conflicts that occasionally erupt into 'contentious episodes', fluid social mobilizations that involve groups 
in some particular issue (McAdam et al. 2001; Tarrow 1994). Privileging the dynamic aspect of conflicts, they suggest that an understanding of mobilizations has to take into account the opportunities and threats that actors face, and the mobilizing structures, framing processes and repertoires that they have access to (see Kriesi et al. 1995; Maloney et al. 2000).

We use the shorthand term 'political opportunity structure' (Tarrow 1994: 85) to address the ways in which mobilizations emerge in specific historical conditions, shaped by both structural social hierarchies and long-term state-society relations, and conjunctural issues such as changes in political-institutional patterns amid ongoing political processes. These can give rise to new political opportunities, such as the emergence of possible allies or vulnerabilities in opponents that encourage collective mobilizations. In the first section, we describe the structures of political opportunity that enabled mobilization in Rio de Janeiro, while making it more difficult in São Paulo.

Collective mobilizations typically involve several sorts of participant. First, there are the authorities, usually agents of government; second, activists who become mobilized to challenge authority or make particular claims; and third, the affected social groups - the populations that both the authorities and activists attempt to represent or control. In order to act politically, organization is required, whether through formal associations or informal networks. In the third section, we describe the contrasting 'mobilizing structures' available to citizens in Rio and São Paulo.

In the middle section, we explore the cultural repertoires - socially and historically rooted ways of interpreting reality (Tilly 1993) - that actors draw on in generating their mobilizing structures and constructing their argumentative strategies and collective identities. Drawing on constructivist approaches, we consider the extent to which actors have come to frame dimensions of their social realities as 'environmental problems' in ways that facilitate environmental mobilization (see also Hannigan 1995). Other authors (Hajer 1995; Irwin 2001b) emphasize the central role of scientific and technical discourse in the social construction of environmental issues, and the ways in which actors use science both to legitimize their positions and to garner public support. That state agencies enrol scientific and technical elites in the construction of discourse coalitions in support of the ecological modernization of capitalist societies has been well documented (Beck 1992; Hajer 1995), yet criticized as one-sided (Irwin 2001b). In this chapter, we consider whether and how citizens and activists, too, draw on the discursive support of scientific and technical elites to support their mobilization strategies.

We begin by comparing the political opportunity structures in which 
the two road-building projects emerged, and go on to consider the socioeconomic conditions and knowledges of the people affected. With those elements at hand, we attempt to explain the very different paths of mobilization that emerged in each case.

\section{Political opportunity structures}

In Rio de Janeiro and São Paulo in the middle of the 1990s, public authorities launched transportation plans to build large beltways encircling the metropolitan perimeters of the cities. Both projects were justified as necessary to overcome 'saturated' traffic conditions in the cities. Both also carried implications for the natural environment as well as for residents in their immediate vicinities. Segments of the projects, including the widening of the Niemeyer Avenue in Rio de Janeiro and the western stretch of the Rodoanel (literally, 'ring road') in São Paulo, passed through various stages of the process of environmental licensing, and in both cases environmental variables were formally considered in defining the routes. In both cases, then, there was a potential environmental conflict. In theory, both projects would have been able to generate mobilization - either for or against them.

A full understanding of the political process involved in the beltway projects requires closer attention to the formal institutional structures in Rio and São Paulo, and the different political opportunities they implied. In Rio de Janeiro, the municipal government initiated the project. A former urban planner from a centre-right party controlled the municipal executive, while a populist politician from a centre-left party controlled the state executive. This political distance resulted in a lack of coordination and even competition between the two levels.

In São Paulo, in contrast, the state government took the lead on the project. While three levels of government were involved - federal, state and municipal - competition between them did not become important, for particular reasons: a timely political crisis assailed the rightist mayor of São Paulo, charged with corruption, while both the state and federal governments were controlled by representatives of the same party.

The projects drew on different connections with national issues. The Rodoanel project was justified primarily for its regional economic benefits, and only secondarily for its impact on traffic in São Paulo. In contrast, the Niemeyer project was always justified in terms of the benefits it would bring for local traffic. In this context, in Rio the municipal executive led the project in isolation, while in São Paulo the state government transformed the Rodoanel into a strategic project for national development.

There were also different relationships between the political executives 